\title{
Heat-Transfer Study of External Superheater of CFB Incinerator
}

\author{
Hong-zhi Sheng, ${ }^{1, *}$ Xiao-lin Wei, ${ }^{1}$ Jun Li, ${ }^{1}$ Wen-dong Tian, ${ }^{1}$ Jian Jin, ${ }^{2}$ Hong-an Jiang, \\ Jun-bin Cao, ${ }^{2}$ and Jun Gao ${ }^{2}$ \\ ${ }^{1}$ Division of Engineering Sciences \\ Institute of Mechanics \\ Chinese Academy of Sciences \\ ${ }^{2}$ Beijing China Sciences General Energy and Environment Co. Ltd \\ China Sciences Group Co. \\ Chinese Academy of Sciences \\ Beijing, P.R. China
}

\begin{abstract}
The heat transfer coefficients for horizontally immersed tubes have been studied in model internally circulating fluidized bed (ICFB) and pilot ICFB incinerators. The characteristics in the ICFB were found to be significantly different from those in a bubbling bed. In ICFB, there is a flowing zone with high velocity, a heat exchange zone, and a moving zone with low velocity. The controllable heat transfer coefficients in ICFB strongly depend on the fluidized velocity in the flowing zone, and also the flow condition in the moving zone. The heat exchange process and suitable bed temperature can be well controlled according to this feature. Based on the results of experiments, a formulation for heat transfer coefficient has been developed. These results were applied to an external superheater of a CFB incinerator with a $450{ }^{\circ} \mathrm{C}$ steam outlet in a waste-to-energy pilot cogeneration plant of $12 \mathrm{MW}$ in Jiaxing City, China.
\end{abstract}

Key words: CFB incinerator; heat transfer coefficients

\section{INTRODUCTION}

$\mathbf{T}$ HE COSTS FOR MSW (Municipal Solid Waste) treatment and disposal are large. A number of MSW incinerators in the United States are privately owned. In other words, the residents pay more than 100 USD for 1 ton of MSW for MSW incineration. In developing countries, MSW incineration is not popular, due to the expensive investigation and operating costs. In China, most
MSW incinerators are grate type, imported from developed countries, and the electricity generation efficiency for MSW incineration (with $320-350{ }^{\circ} \mathrm{C}$ steam temperature) is much lower than a coal-firing power plant with a higher steam temperature. Facing the growing volume of MSW, China has to develop a new technology to incinerate MSW in an economic way-low investigation and higher efficiency.

Many efforts were made to raise the efficiency of elec-

*Corresponding author: Institute of Mechanics, Chinese Academy of Sciences, Bei Si Huan Xi Lu. 15, Beijing 100080, P.R. China. Phone: 86-10-62657767;Fax: 86-10-62561284;E-mail: hz_sheng@imech.ac.cn 
tricity generation, and the most effective way is to raise the steam temperature. However, even when very expensive alloys were employed, or double-furnaces were tried, the steam temperature is not high enough, since the $\mathrm{HCl}$ corrosion problem is very serious at higher steam temperature condition for MSW incineration.

The external superheater for the Circulating Fluidized Bed (CFB) incinerator is a good choice to avoid the $\mathrm{HCl}$ corrosion problem. Since the $\mathrm{HCl}$ concentration at the ash outlet of the high-temperature separator (cyclone type) of CFB incinerator is only $12.6 \mathrm{ppm}$, the corrosion can be minimized. The important thing is how to control the heat transfer between the hot ash and the steam in a superheater. An uneven air distribution, named Internal Circulating Fluidized Bed (ICFB) technology, was employed. This type of fluidized bed has special heat transfer characteristics, which can control the heat transfer rate easier, and is different from a bubbling bed with even air distribution. This paper describes the heat transfer coefficient study at an ICFB incinerator for MSW incineration, and the results for uneven air distribution are applied for external superheater design.

\section{EXPERIMENTAL STUDY OF THE HEAT-TRANSFER COEFFICIENT}

How to deal with the domestic and industrial wastes without further contamination is one of the most important environmental issues. Fluidized bed combustion has advantages of high combustion efficiency and low pollutant emission. CFB combustion is a newly developed technology for MSW incineration with many advantages, such as lower primary air pressure and higher combustion intensity, etc.

The ICFB is a special fluidized bed, in which the bed consists of moving, flowing, and heat exchange zones. These zones are established by uneven distribution of fluidized air. The bed structure and the air distribution are designed for MSW incineration. In ICFB, the heat exchange zone can be arranged to allow a certain amount of heat transferred through immersed tubes. This heat flux transferred is proportional to the heat release rate from waste combustion, and varies with air velocity in the bed. This helps to suppress the combustion fluctuations of MSW, which are induced by the fluctuation of heating value or feeding rate of MSW. This is one of the most difficult technological issues in waste incineration. By heat flux control, combustion stability is improved, and energy in MSW is recovered more efficiently.

The heat exchange characteristics of immersed tubes in a bubbling bed have been studied in the past. The results were extensively used in the design and operation of Bubbling Fluidized Bed (BFB) boilers. However, the studies on ICFB were relatively limited except for a few investigations by Ebara Company, Japan, (Ohshita et al., 1994), which developed ICFB with partition boards. Because of effect of the flowing zone, the heat transfer rate in the heat exchange zone without partition boards (Fig.1) is different from Ebara's approach, which utilized partition boards. The heat flux is strongly affected by the flow condition in the flowing zone in this configuration. Heat transfer coefficients cannot be derived from the Ebara's study. The effects of interaction between the flowing zone and the heat exchange zone on the heat exchange rate of the immersed tube were studied experimentally here, and the heat transfer coefficient between the bed materials and immersed tube was obtained from both a cold model and a thermal model

Because of the symmetry of ICFB, only half of the fluidized bed, with one heat transfer zone and one flowing zone, was utilized in the cold model. The testing apparatus is shown in Fig. 2. The effective area of the air distribution plane is $130 \times 370 \mathrm{~mm}^{2}$, with a punching rate of $6 \%$. The area ratio of the moving zone, the flowing zone, and the heat transfer zone is $1: 2: 1$. The height of apparatus is $500 \mathrm{~mm}$. Air streams at room temperature for these three zones are supplied through corresponding air chambers under the air distributor. The fluidizing ratios in the moving zone, the flowing zone, and the heat transfer zone were set to $1.5,3.0-6.0$, and $0.0-4.0$, respectively. In this study, cold sand grains with a mean diameter of $0.40 \mathrm{~mm}$ were used as a fluidized medium. The still bed height is about $130 \mathrm{~mm}$. The effective heat transfer length of two U-shaped immersed tubes was 180

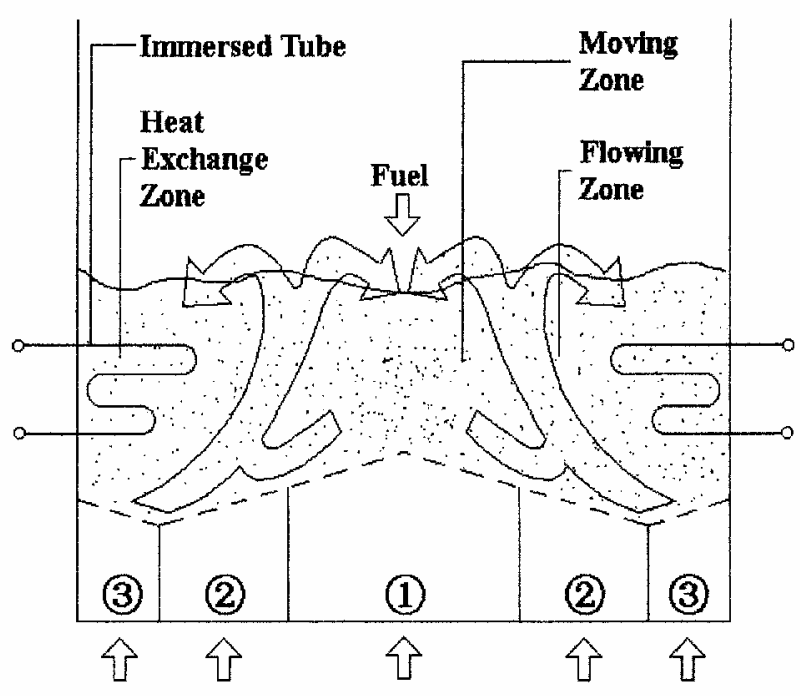

Figure 1. Schematic of ICFB without partition board. 


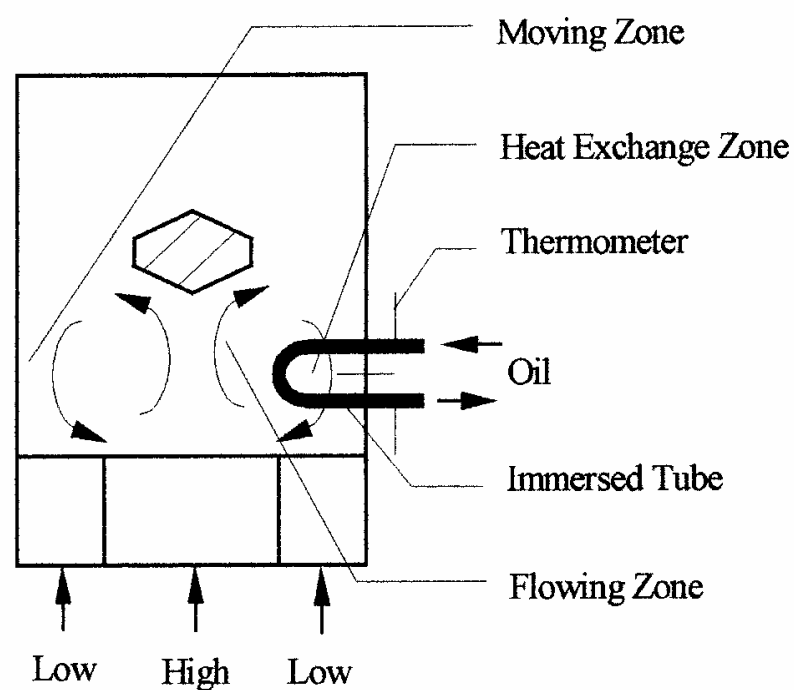

Figure 2. Schematic of experimental system of heat transfer characteristics for immersed tube.

$\mathrm{mm}$. The tubes have the inner and outer diameters of 16.8 and $21.4 \mathrm{~mm}$, respectively. High-temperature lubricating oil was fed into the tube with a relatively high rate of 0.3 $\mathrm{L} / \mathrm{s}$ to maintain the tube wall at high temperature. The lubricating oil was heated up to two temperature levels of 140 and $160^{\circ} \mathrm{C}$ by a special electrical heater. The heater was controlled to keep the oil temperature constant.

Two Pt thermocouples were installed respectively on the tube. One was located at the tube top, that is, at the rear stagnant point of the incoming air-sand flow. The other was set at the tube side, that is, $90^{\circ}$ downstream of the front stagnant point. They were arranged $15 \mathrm{~mm}$ apart in the tube axis direction. The temperature of air-sand two-phase bed was measured by two other thermocou-

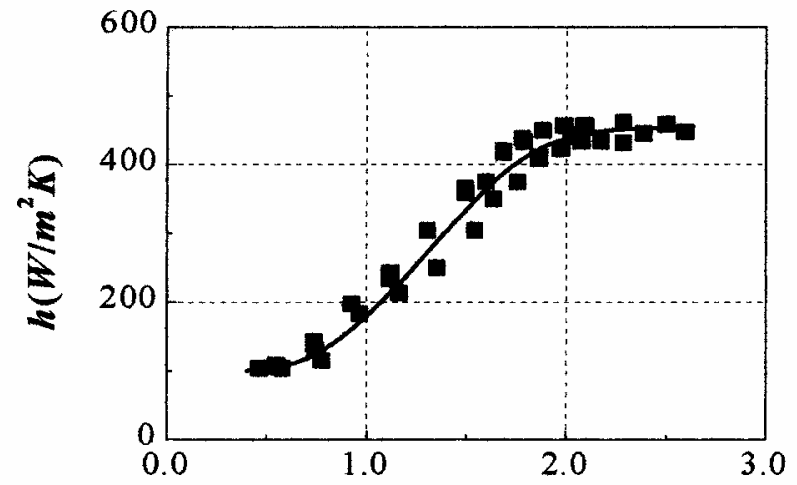

\section{Fluidized Ratio}

Figure 3. Heat transfer coefficient with different fluidized ratio $\left(G_{f}^{\prime}=3.20\right)$. ples. They were set inside of the heat exchange zone and arranged $100 \mathrm{~mm}$ apart vertically.

For a bubbling bed, at the air velocity range between the minimum fluidized velocity $u_{\mathrm{mf}}$ and optimum fluidized velocity $u_{\text {opt }}$, the heat transfer coefficient increases rapidly with the increase of air velocity, and the heat transfer coefficient reaches the maximum value at the optimum fluidized velocity.

In ICFB, variation of fluidized velocity in the flowing zone has significant influence on the heat exchange characteristics in adjacent zones. Within an operation range below the $u_{\mathrm{opt}}$, the heat transfer coefficient increases with fluidized velocity. But the increase slope in the ICFB is relatively smoother than that in the bubbling bed. This presents a preferred feature to control the heat transfer rate and bed temperature by regulating the fluidized velocity.

Figures 3-5 show the heat transfer features of the immersed tube in ICFB (without partition boards) under three fluidized ratios of 3.20, 4.30, and $5.30 u_{\mathrm{mf}}$ in the flowing zone. Under these conditions, air-sand two-phase flow in the heat transfer zone is greatly intensified by the flowing zone. Thus, the heat transfer coefficient is significantly increased even if the heat transfer zone does not reach the minimum fluidized velocity. In this case, with the increase of the fluidized ratio in the heat transfer zone, the curve of the heat transfer coefficient in ICFB is not as sharp as that in the bubbling bed. This feature can be used to control the heat flux by means of adjusting air velocity in the heat transfer zone. This is a prominent advantage of ICFB. The temperatures in the immersed tube and fluidized bed may have some influences on the heat transfer coefficients while the fluidized ratio remains the same, so the results may be verified for higher temperature conditions in a pilot ICFB incinerator.

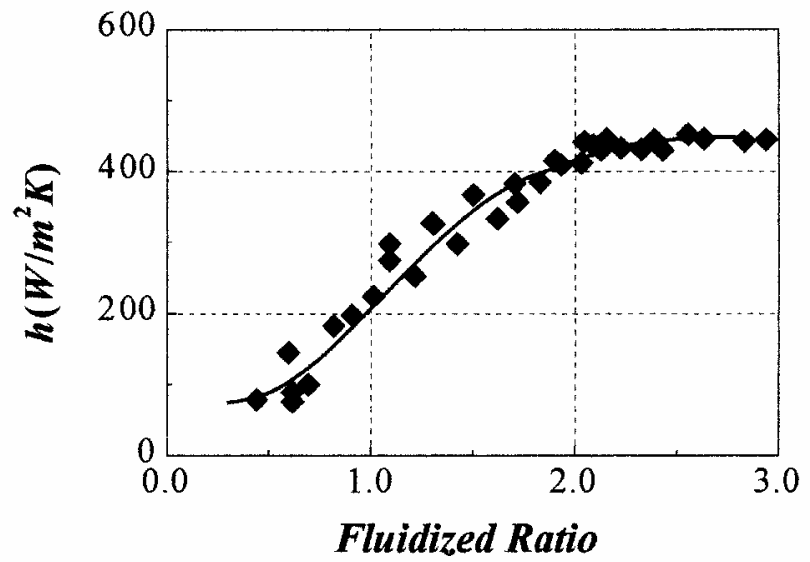

Figure 4. Heat transfer coefficient with different fluidized ratio $\left(G_{f}^{\prime}=4.30\right)$. 


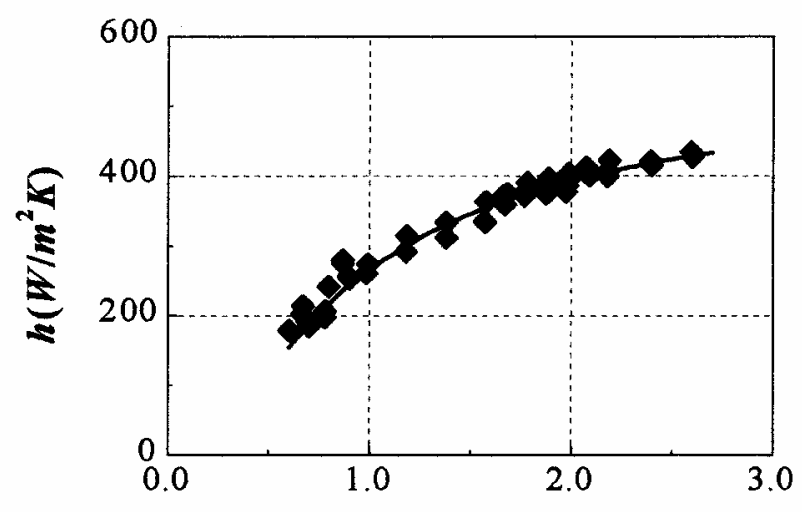

Fluidized Ratio

Figure 5. Heat transfer coefficient with different fluidized ratio $\left(G_{f}^{\prime}=5.40\right)$.

Figure 6 shows the effect of the fluidized ratio at different fluidized zones on the heat transfer coefficients. Between the minimum and the optimum fluidized velocity, the larger the fluidized ratio $G_{f}$ is, the smoother the slope of the curve becomes. With this heat transfer characteristic, both heat flux through the immersed tube and fluidized bed temperature can be controlled efficiently.

The air flow rate in the flowing zone of ICFB is much higher than that in the bubbling bed. The intensified air flow should change the heat transfer characteristics of the immersed tube. Some corrections to account for this influence are needed. According to experimental results, an empirical equation for heat transfer Nusselt Number $\mathrm{Nu}$ of immersed tube in ICFB is derived as follows; the details are shown in Tian et al. (1999).

$$
\begin{gathered}
N u=\left(-0.787 G_{f}{ }^{\prime}+6.24\right) \times(1-\varepsilon) \\
\times\left[\left(\frac{\mathrm{G}_{h} \mathrm{~d}_{\text {out }} \rho_{\mathrm{s}}}{\rho_{\mathrm{g}} \mu_{\mathrm{g}}}\right) \times\left(\frac{\mu_{b}^{2}}{d_{p}^{3} \rho_{s}^{2} g}\right)\right]^{0.325} \\
\times\left(\frac{\rho_{s} c_{\mathrm{ps}} d^{3 / 2}}{k_{g}} g^{\frac{g^{\prime}}{2}}\right)^{0.23} \times \operatorname{Pr}^{0.3}+3.42 G_{f}^{\prime}-21.25
\end{gathered}
$$

Equation (1) is fitted under the condition of and $G_{\mathrm{mf}, h}^{\prime} \leq$ $G_{h}^{\prime} \leq G_{\mathrm{opt}, h}^{\prime}$ and $d_{p}<1 \mathrm{~mm}$. Comparisons of the experimental data with Equation (1) are shown in Fig 7. The results predicted by Equation (1) are very consistent with the experiments. The bias errors are less than $20 \%$. The larger the volume for $\mathrm{Nu}$ is, the smaller the error.

\section{THE EXTERNAL SUPERHEATER}

$\mathrm{HCl}$ corrosion is a serious barrier to raising steam temperature to $400^{\circ} \mathrm{C}$ or higher, and the system efficiency

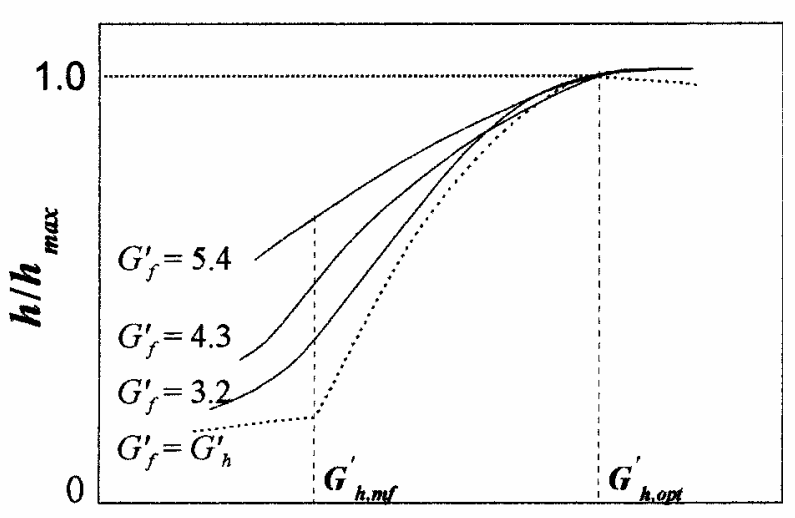

Fluidized Ratio

Figure 6. Heat transfer coefficient variation with fluidized ratio at different fluidized zone.

for MSW incineration boiler below these temperatures is not satisfactory.

The external superheater for CFB incinerator provides the best solution to solve this problem. The superheater is a fluidized bed heat exchanger connected to the outlet of high-temperature separator. The schematic structure of the CFB waste-to-energy boiler with external superheater is shown in Fig. 8.

An external superheater is designed between the cyclone and the ash-recycle valve, and the energy stored in the hot ash is used to superheat the steam. According to

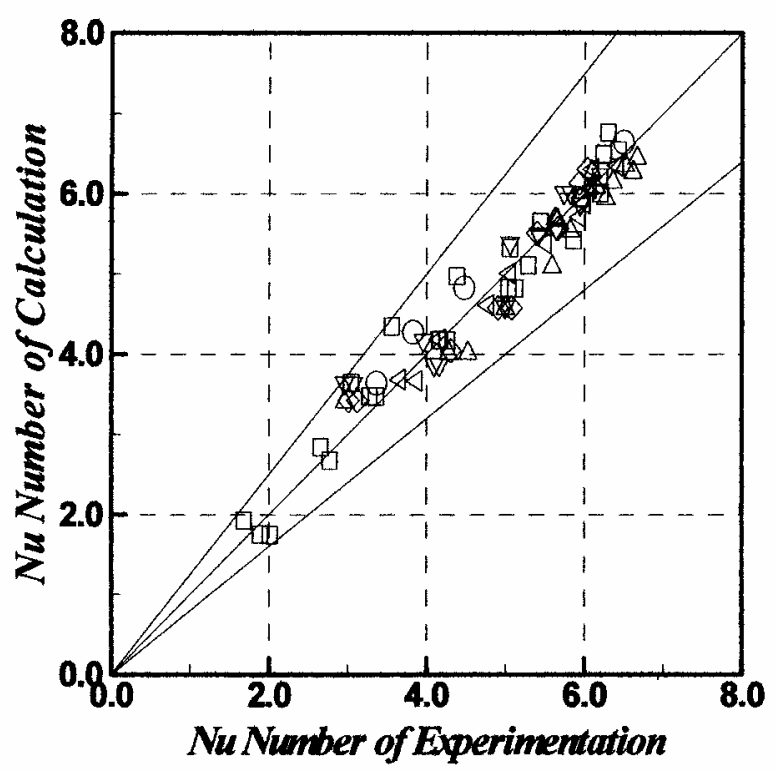

Figure 7. Comparisons between the experimental data and value calculated by Equation (1). 


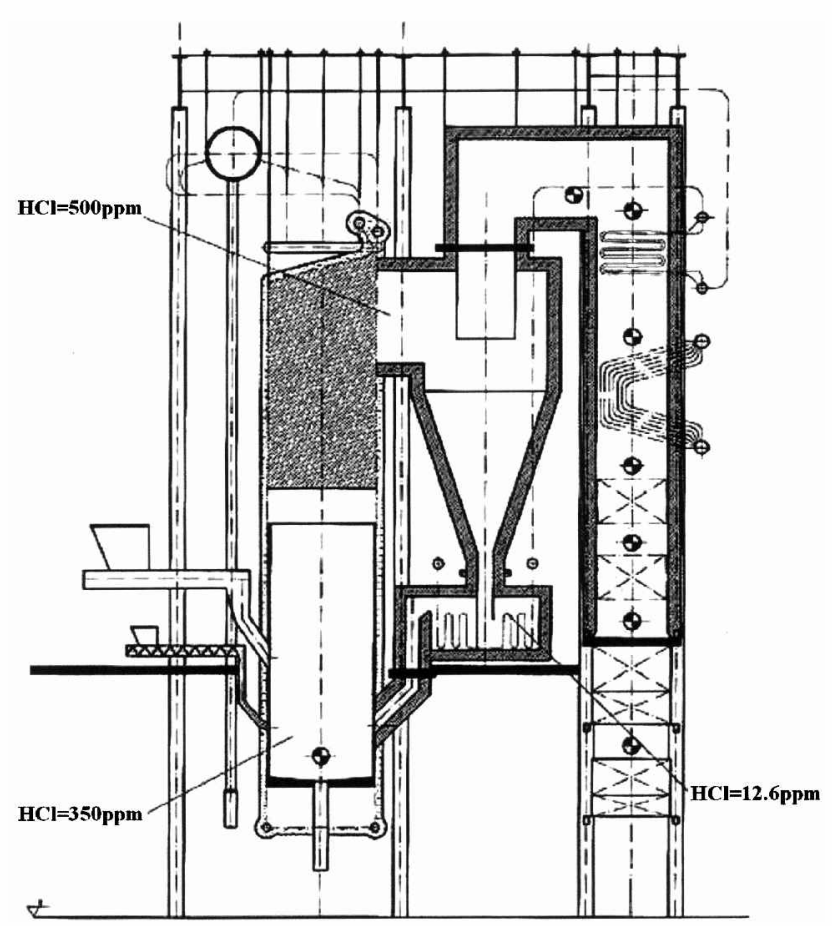

Figure 8. Structure of CFB waste-to-energy boiler with external superheater.

our measurement, the $\mathrm{HCl}$ concentration at inlet of external superheater is $12.6 \mathrm{ppm}$, only $1 / 40$ of that in flue gas. Therefore, inside the external superheater, the $\mathrm{HCl}$ corrosion can be eliminated. In this design, the stream's temperature at the superheater can be raised to $500{ }^{\circ} \mathrm{C}$ or higher without the use of special alloy application. Compared with normal design criteria of $320^{\circ} \mathrm{C}$ steam temperature, the efficiency of electricity generation can be raised to $50-70 \%$. With a higher cycling ratio in CFB incinerator, there is sufficient energy to accomplish this.

The most important thing for external superheater is the method used to control the heat transfer between the hot ash and the steam in the superheater. An uneven air distribution, ICFB technology can be employed. As mentioned above, this type of fluidized bed has special heattransfer characteristics, different from a bubbling bed with even air distribution. The heat transfer rate is easier controlled by ICFB technology.

The results for heat transfer mentioned in this paper can be applied to design the external superheater in CFB incinerator. When the air speed varies in different zones, the heat transfer coefficient can be controlled in a wide range. So the transferred heat from circulating materials to superheater can be controlled in a relatively stable range to meet the requirements of different load and dif- ferent waste at different seasons with different moisture content for incineration.

\section{THE DEMO-PLANT IN JIAXING CITY}

The external superheater design was employed at a demonstration waste-to-energy plant with steam parameters of $450^{\circ} \mathrm{C}$ and $3.82 \mathrm{MPa}$. At the first stage, this project built two lines of incineration with one $12 \mathrm{MW}$ turbogenerator in the yard of Bu-Yun Co-Generation Plant at Jiaxing City, Zhejiang Province, China. The Bu-Yun Plant has two $35 \mathrm{t} / \mathrm{h}$ coal-fired steam boilers at $450^{\circ} \mathrm{C}$ and $3.82 \mathrm{MPa}$, and two vacuum turbo-generators with steam extraction of $16 \mathrm{t} / \mathrm{h}$ each, the steam extracted at $310^{\circ} \mathrm{C}$ and $1.0 \mathrm{MPa}$.

Since the lower heating value of MSW in China is only $4,000-5,000 \mathrm{~kJ} / \mathrm{kg}$ at present, and the total MSW in Jiaxing City is only 600 t/day. We designed two MSWCoal cofiring boilers to deal with this concern. The plant burns $600 \mathrm{t} /$ day MSW $(5,000 \mathrm{~kJ} / \mathrm{kg})$ mixed with $120 \mathrm{t} /$ day coal $(21,000 \mathrm{~kJ} / \mathrm{kg})$, and can produce $65 \mathrm{t} / \mathrm{h}$ steam $\left(450^{\circ} \mathrm{C}\right.$, $3.82 \mathrm{MPa}$ ), and $12 \mathrm{MW}$ electricity ( $24 \mathrm{hr} /$ day) by a vacuum turbo-generator. When the lower heating value is higher and the MSW amount increases, the coal can be reduced. Cofiring with coal can keep the combustion and steam production stable, and raises the efficiency of electricity generation.

The Project Feasibility Study shows that the economics for this project are very good. When the sale price of electricity is 5.5 cents (US), the governmental allowance is 2.4 USD for each ton of MSW, and the total investment is 12.8 million USD ( 2 million USD can be saved due to sharing some facilities with existing system in the plant). The investment will be recovered within 9 years and IIR (Internal Interests Return) of this project will be $9.78 \%$. In this case, this demo-plant shows the economic feasibility for MSW incineration.

In addition to economic advantage, cofiring with coal can reduce air pollution and PCDDs, since the temperature in the furnace is higher enough and the sulfur in the coal will reduce the PCDDs reformation.

\section{CONCLUSIONS}

1. Uneven air distribution technology (ICFB without partition boards) can provide a controllable feature of heat transfer.

2. An external superheater can avoid the $\mathrm{HCl}$ corrosion for higher steam parameters.

3. Cofiring of waste with coal can provide stable com- 
bustion and steam production to get better economic benefit and less air pollution.

\section{NOMENCLATURE}

$c_{p} \quad$ Specific heat at constant pressure

$d \quad$ Diameter

$g^{\prime} \quad$ Gravitational acceleration

$G \quad$ Fluidized velocity

$G^{\prime} \quad$ Fluidized ratio

$u_{\mathrm{mf}} \quad$ Minimum fluidized velocity

$k \quad$ Conductivity

Pr Prandtl number

$\mu \quad$ Viscosity

$\rho \quad$ Density

$\kappa \quad$ Amendatory Factor

$\epsilon$ Porosity

$b \quad$ Bed

$f \quad$ Flow or flow zone, fluidization

$g \quad$ Gas

$h \quad$ Heat exchange zone mf Minimum fluidization

opt Optimum state

out Outside tube

$p \quad$ Particle

$s \quad$ Solid

\section{ACKNOWLEDGMENT}

The authors gratefully acknowledge the work supported by the Key Projects of Chinese Academy of Sciences and National Foundation of Sciences of China.

\section{REFERENCES}

OHSHITA, T., HIGO, T., KOSUGI, S., and INUMARU, N. (1994). Formation of internally circulating flow and control of overall heat-transfer coefficient in a fluidized-bed boiler. Heat Transfer Jap. Res. 32(4), 349-363

TIAN, W., HAO, J., WEI, X., LI, J., WU, D., and SHENG, H. (1999). A study on heat transfer for immersed tube in internally circulating fluidized bed. J. Thermal Sci. 8(3), 190-195. 